\title{
Role of infection in the middle lobe syndrome in asthma
}

Chaim Springer, Avraham Avital, Natan Noviski, Chana Maayan, Ilana Ariel, Paul Mogle, Simon Godfrey

\begin{abstract}
Twenty one children with asthma aged 1.0-10.5 years (mean (SD) $3.3(2.5)$ years) were admitted to the hospital to evaluate pulmonary right middle lobe or lingular collapse lasting one to 12 months (mean (SD) 4.4 (3.8) months). Seven children had mild asthma and were treated with inhaled $\beta_{2}$ agonists as needed. Nine had moderate asthma treated with either sodium cromoglycate or slow release theophylline. Five had severe asthma treated with inhaled steroids. Each child underwent fibreoptic bronchoscopy under local anaesthesia and a bronchoalveolar lavage. Differential cell counts of the lavage fluid revealed predominance of neutrophils in 12 patients $(57 \%)$. In nine of these patients cultures grew pathogenic bacteria, mainly Haemophilus influenzae and Streptococcus pneumoniae. There was no correlation between the severity of asthma and a positive bacterial culture. There was also no correlation between the duration of the right middle lobe collapse and a positive culture. We conclude that longstanding right middle lobe collapse in asthmatic children is often associated with bacterial infection.
\end{abstract}

Pulmonary segmental or lobar collapse is a common complication of childhood asthma. It has been reported that about $5-10 \%$ of all children hospitalised with acute asthmatic attacks had radiographic evidence of lobar collapse, the right middle lobe being involved most frequently. 12
The incidence of infection in the lobar collapse in asthmatic patients is not clear. Hopkirk and Stark reported five asthmatic patients with repeated episodes of pulmonary atelectasis. ${ }^{3}$ Sputum culture grew Haemophilus influenza in only one patient, and in four patients bronchial aspirates were negative for bacteria or fungi. Dees and Spock could not find any specific diagnostic help in sputum or bronchoscopic aspirates in 30 children with right middle lobe collapse. ${ }^{4}$ Also, Billing and Darling reported normal flora from bronchial secretions in 11 children with right middle lobe atelectasis. $^{5}$

The purpose of this study was to examine the incidence of infection in the right middle lobe collapse in a group of asthmatic children.

\section{Patients and methods}

Over a period of four years, 21 asthmatic children (16 boys and five girls) aged 1-10.5 years were admitted to Hadassah University Hospital for the evaluation of right middle lobe (20 patients) or lingular (one patient) collapse (table 1). The duration of the collapse ranged from one to 12 months. A history of recurrent febrile episodes was positive in 13 patients. Regular antiasthmatic treatment in these patients consisted of inhaled beclomethasone dipropionate or budesonide in five children classified as severe asthma, sodium cromoglycate in eight and slow release theophylline in one classified as moderate asthma, and inhaled $\beta_{2}$ agonists as needed in seven children classified as mild asthma.
Hadassah University Institute of Pulmonology Chaim Springer Avraham Avital Natan Noviski Chana Maayan Simon Godfrey

Department of Pathology Ilana Ariel

Department of Radiology Paul Mogle

Correspondence to: Dr Chaim Springer, Institute of Pulmonology, Hadassah University Hospital, Ein Kerem Jerusalem, Israel.

Accepted 17 January 1992
Table I Patient characteristics, bronchoalveolar differential cell counts, and culture results

\begin{tabular}{|c|c|c|c|c|c|c|c|}
\hline \multirow{2}{*}{$\begin{array}{l}\text { Patient } \\
\text { No }\end{array}$} & \multirow[t]{2}{*}{ Sex } & \multirow{2}{*}{$\begin{array}{l}\text { Age } \\
\text { (years) }\end{array}$} & \multirow[t]{2}{*}{ Culture } & \multicolumn{4}{|c|}{$B A L \%$ cell count } \\
\hline & & & & Neutrophils & Lymphocytes & Macrophages & Eosinophils \\
\hline $\begin{array}{r}1 \\
2 \\
3 \\
4 \\
5 \\
6 \\
7 \\
8 \\
9 \\
10 \\
11 \\
12 \\
13 \\
14 \\
15 \\
16 \\
17 \\
18 \\
19 \\
20 \\
21\end{array}$ & $\begin{array}{l}M \\
M \\
M \\
M \\
M \\
M \\
M \\
M \\
F \\
F \\
M \\
M \\
M \\
M \\
M \\
M \\
M \\
F \\
F \\
M \\
M\end{array}$ & $\begin{array}{r}2 \cdot 0 \\
2 \cdot 0 \\
3 \cdot 0 \\
1 \cdot 0 \\
1 \cdot 5 \\
5 \cdot 5 \\
1 \cdot 5 \\
2 \cdot 0 \\
1.0 \\
4 \cdot 0 \\
4 \cdot 0 \\
9 \cdot 0 \\
1 \cdot 5 \\
4 \cdot 0 \\
10 \cdot 5 \\
3 \cdot 0 \\
3 \cdot 5 \\
3 \cdot 0 \\
4 \cdot 0 \\
2 \cdot 0 \\
2 \cdot 0\end{array}$ & $\begin{array}{l}H \text { influenzae } \\
H \text { influenzae } \\
\text { Negative } \\
\text { Negative } \\
\text { S pneumoniae } \\
H \text { influenzae } \\
H \text { influenzae } \\
\text { Negative } \\
\text { Negative } \\
\text { Acinetobacter sp } \\
\text { Negative } \\
H \text { influenzae } \\
\text { Negative } \\
\text { Branhamella catarrhalis } \\
\text { Negative } \\
\text { Negative } \\
H \text { influenzae } \\
\text { Negative } \\
S \text { pneumoniae } \\
\text { Negative } \\
\text { Negative }\end{array}$ & $\begin{array}{r}95 \\
62 \\
68 \\
50 \\
50 \\
77 \\
95 \\
20 \\
20 \\
85 \\
5 \\
68 \\
30 \\
25 \\
25 \\
5 \\
75 \\
70 \\
70 \\
20 \\
30\end{array}$ & $\begin{array}{r}26 \\
3 \\
20 \\
10 \\
10\end{array}$ & $\begin{array}{r}5 \\
38 \\
6 \\
50 \\
50 \\
20 \\
5 \\
60 \\
70 \\
15 \\
85 \\
32 \\
70 \\
75 \\
45 \\
95 \\
25 \\
10 \\
20 \\
80 \\
70\end{array}$ & 5 \\
\hline
\end{tabular}


Bronchoscopies were performed as part of our routine investigations to evaluate longstanding lobar collapse, using a $3.6 \mathrm{~mm}$ fibreoptic bronchoscope (Olympus BF 3C20). Sedation was achieved using oral chloral hydrate (50-100 $\mathrm{mg} / \mathrm{kg}$ and intravenous pethidine $1-2 \mathrm{mg} / \mathrm{kg}$. Lignocaine hydrochloride up to $5 \mathrm{mg} / \mathrm{kg}$ was used for local anaesthesia of the airways. Heart rate and oxygen saturation by pulse oximetry were monitored during the procedure. Bronchoalveolar lavage of the right middle lobe or the lingula was performed using buffered saline. The recovered bronchoalveolar lavage (BAL) fluid was cytocentrifuged (Hettich Universal) for 10 minutes at $3000 \mathrm{rpm}$. The preparation was fixed in $96 \%$ ethyl alcohol and stained by haematoxylin and eosin for differential cell count. Aliquots of the fluid were Gram stained and cultured for bacteria. Samples were cultured for bacteria only if squamous epithelial cells were not seen on Gram stains.

Analysis by $\chi^{2}$ and $t$ tests was performed when appropriate; $p$ value was considered significant if $<0.05$.

\section{Results}

Airway anatomy was normal in 20 patients. Narrowing of the orifice of the right middle lobe bronchus was observed in one patient. Mucopurulent secretions from the right middle lobe bronchus were observed in three patients and from the lingula in one patient. Differential cell counts of the BAL revealed a predominance of neutrophils ( $\geqslant 50 \%$ of the total cell count) in 12 out of the 21 patients $(57 \%)$, (table 1 ). In nine of these 12 patients and in patient 14 with $\mathrm{BAL}$ neutrophils of $25 \%$ ( $48 \%$ of all patients), cultures resulted in a poor growth of an upper respiratory tract flora and a heavy growth of a single pathogenic bacterium ( $H$ influenzae, $\beta$ lactamase negative and Streptococcus pneumoniae being the most frequent). In all the other patients cultures resulted only in a poor growth of upper respiratory flora.

There was a significant correlation between a positive culture and the predominance of neutrophils in the BAL fluid (table 2). No correlation was found between a positive $\mathrm{BAL}$ culture and a history of recurrent febrile episodes, nor was there any correlation with white cell count in peripheral blood (mean (SEM) 9120 (780) in patients with positive cultures and 11244 (1166) in patients with negative cultures, $p=0 \cdot 154)$. No correlation was found between the severity of asthma and a positive bacterial culture (table 3 ). In addition, no correlation was found between the duration of the collapse and a positive BAL culture $(4 \cdot 0$ $(1 \cdot 4)$ months in patients with positive cultures

Table 2 Correlation between BAL cultures and differential cell counts. Values are mean (SEM) in percentages

\begin{tabular}{lll}
\hline $\begin{array}{l}\text { Predominant } \\
\text { BAL cells }\end{array}$ & $\begin{array}{l}\text { Positive } \\
\text { culture }\end{array}$ & $\begin{array}{l}\text { Negative } \\
\text { culture }\end{array}$ \\
\hline $\begin{array}{l}\text { Neutrophils } \\
\text { Macrophages }\end{array}$ & $70(7)^{*}$ & $26(6)^{*}$ \\
\hline
\end{tabular}

${ }^{*}$ Significance by unpaired $t$ test: ${ }^{*} p=0.0001 ;{ }^{*} p=0.001$.
Table 3 Bronchoalveolar lavage cultures related to severity of asthma

\begin{tabular}{lll}
\hline Asthma severity & $\begin{array}{l}\text { Positive } \\
\text { culture }\end{array}$ & $\begin{array}{l}\text { Negative } \\
\text { culture }\end{array}$ \\
\hline Mild & 3 & 4 \\
Moderate & 4 & 5 \\
Severe & 3 & 2 \\
\hline
\end{tabular}

$\chi^{2}$ test: $\mathrm{p}=0.82$.

and $4.5(1.0)$ months in patients with negative cultures, $p=0 \cdot 73$ ).

All the patients with positive cultures were treated with appropriate antibiotics according to sensitivity. In all but one patient (patient 19) complete resolution of the collapsed lobe was observed within a few weeks (up to three months).

\section{Discussion}

Collapse of the right middle lobe or the lingula is well described in asthmatics, ${ }^{1-3}$ although no satisfactory explanation of the phenomenon has yet been found. The term right middle lobe syndrome was first described by Graham and colleagues and was thought to be an obstructive atelectasis due to the compression of the right middle lobe bronchus by enlarged peribronchial lymph nodes. ${ }^{6}$ However, enlarged peribronchial lymph nodes are likely to be found mainly in middle lobe bronchiectasis and are probably not the cause of the collapse in asthmatic patients. Culiner suggested that impaired or absent collateral ventilation is the main cause for the increased incidence of right middle lobe atelectasis. $^{7}$

Our study may shed new light on the pathogenesis of the right middle lobe collapse in asthmatic children by showing that it is associated with bacterial infection in about $50 \%$ of the patients examined. This proportion of positive cultures may have been underestimated due to the widespread use of antibiotics by the primary physicians. It is possible that BAL specimens were contaminated by bacteria from the upper respiratory tract introduced to the lower airways by the bronchoscope. It has been shown that the presence of less than $1 \%$ squamous epithelial cells and more than $10^{5}$ colony forming units in BAL fluid were associated with bacterial infections of the lower respiratory tract. ${ }^{89}$ In our study we cultured specimens only if squamous epithelial cells were not detected in Gram stains and considered as a positive culture only those with a heavy growth of a single pathogen. Moreover, all the BAL samples with positive cultures (except in patient 14) were associated with a predominance of neutrophils. In three patients (numbers 3, 4, 18) BAL differential cell counts revealed $50 \%$ or more of neutrophils and negative cultures. This may be due to a recent unreported antibiotic treatment and probably not to bronchial inflammation caused by asthma since it has been reported that neutrophils are only slightly increased in stable asthma. ${ }^{10}$ It should be noted that our findings are different from those of Hopkirk and Stark ${ }^{3}$ and those of Billing and Darling 5 who found either sterile cultures or normal flora in most patients. However, Dees 
and Spock although stating that they could not find any specific diagnostic help in sputum or bronchial aspirates, report positive bacterial cultures from bronchial aspirates in 11 out of 29 $(38 \%)$ examined. ${ }^{4}$

In the present study, in all patients except one complete resolution of the collapsed lobe was observed within three months. As this was an open study we cannot be sure that the resolution in the patients with a positive culture was due only to the antibiotic treatment. However, we believe that infection should be considered in every patient with a longstanding lobar collapse unresponsive to aggressive antiasthmatic treatment, and an appropriate antibiotic should be added to these patients. Failure to treat a longstanding lobar collapse may result in chronic infection and bronchiectasis. ${ }^{11} 12$

As no correlation was found between positive cultures and recurrent febrile episodes or leucocytosis in the peripheral blood, such criteria cannot differentiate infected from non-infected patients. The incidence of infection was similar among the mild, moderate, and severe asthmatic patients (table 3 ). As the severe asthmatics were receiving inhaled corticosteroids, it suggests that such treatment does not predispose children to pulmonary bacterial infections.

In conclusion, we have shown that longstanding right middle lobe collapse in asthmatic children is often associated with bacterial infections. It is suggested that every asthmatic child with this complication should be treated with aggressive antiasthmatic treatment and chest physiotherapy. Failure of such an approach will justify additional antibiotic therapy to treat $H$ influenzae and $S$ pneumoniae as the most common pathogens.

1 Eggleston PA, Ward BH, Pierson WE, Bierman CW. Radiographic abnormalities in acute asthma in children. Pediatrics 1974;54:442-9.

2 Luhr J. Atelectasis in asthma during childhood. Nord Med 1958;60:1199.

3 Hopkirk JAC, Stark JE. Unilateral pulmonary collapse in asthmatics. Thorax 1978;33:207-10.

4 Dees SC, Spock A. Right middle lobe syndrome in children JAMA 1966;197:78-84.

5 Billing DM, Darling DB. Middle lobe atelectasis in children. Am F Dis Child 1972;123:96-8

6 Graham EA, Burford TH, Meyer JH. Middle lobe syndrome. Postgrad Med 1948;4:29-34.

7 Culiner MM. The right middle lobe syndrome, a non obstructive complex. Dis Chest 1966;50:57-66.

8 Thorpe JE, Baughman RP, Frame PT, Wesseler TA, Staneck JL. Bronchoalveolar lavage for diagnosing acute bacteria pneumonia. J Infect Dis 1987;155:855-61.

$9 \mathrm{Kahn}$ FW, Jones JM. Diagnosing bacterial respiratory infection by bronchoalveolar lavage. F Infect Dis 1987;155: 862-9.

10 Reynolds HY. Bronchoalveolar lavage. State of the art. $A m$ Rev Respir Dis 1987;135:250-63.

11 Wagner RB, Johnston MR. Middle lobe syndrome. Ann Thorac Surg 1983;35:679-86.

12 Livingston GL, Holinger LD, Luck SR. Right middle lobe syndrome in children. Int $\mathcal{f}$ Pediatr Otorhinolaryngol 1987;13:11-23. 